\title{
Experimental and FE study of hybrid laminates aluminium carbon-fibre joints with different lay-up configurations
}

\author{
Ricardo J.C. Carbas ${ }^{1,2,}{ }^{*}$, Miguel P. Palmares ${ }^{2}$, and Lucas F.M. da Silva ${ }^{2}$ \\ ${ }^{1}$ Institute of Science and Innovation in Mechanical and Industrial Engineering (INEGI), Faculty of Engineering, \\ University of Porto, Porto, Portugal \\ ${ }^{2}$ Department of Mechanical Engineering, Faculty of Engineering, University of Porto, Porto, Portugal
}

Received: 10 November 2019 / Accepted: 8 December 2019

\begin{abstract}
The use of composite materials in industry is growing due to various technological advances in composite materials accompanied by improvements in the structural adhesives used to bond them. Fibre metal laminates (FML's) are hybrid composite structures based on thin sheets of metal alloys and plies of fibrereinforced polymeric materials. The fibre/metal composite technology combines the advantages of metallic materials and fibre-reinforced matrix systems. The aim of the present study is to use a concept similar to that used in FML to increase the peel strength of composite materials and increase the joint strength of hybrid laminates aluminium carbon-fibre adhesive joints. Carbon fibre-reinforced plastic (CFRP) composites were modified by including one or several aluminium sheets during the laminate manufacture to enhance the composite through the thickness properties. The objective was to identify the joint configuration that gives the best joint strength improvement in relation to the CFRP only reference joint. An adhesive developed for the aeronautical industry was used to manufacture single lap joints for tensile testing. Experimental and numerical studies were undertaken on modified CFRP joints to investigate the joint strength of different lay-up solutions to prevent delamination of adherends.
\end{abstract}

Keywords: Film epoxy adhesive / carbon fibres / fibre metal laminates / mechanical properties / phosphoric acid anodizing / finite element analysis / damage mechanics

\section{Introduction}

The use of composite materials has increased exponentially throughout the years. The combination of their excellent mechanical properties and low weight makes these materials natural alternative to metallic alloys in the transport industry. Nowadays, these materials have a competitive price and compete with metallic alloys in a wide range of applications, from the aerospace industry to the automotive industry or even sports goods. One of the advantages of adhesive bonding is that it enables the joining of dissimilar materials. Thus, it is possible to bond fibre-reinforced plastics to metals or other composites. Banea and da Silva [1] review adhesive joints in composite materials. Another recent review on the subject is given by Pethrick [2]. Composite materials can be of many types and are increasingly being used due to their excellent strength to weight ratio. The behaviour of composites is highly anisotropic with respect to both stiffness and strength. In

\footnotetext{
* e-mail: carbas@fe.up.pt
}

the fibre direction, unidirectional composites can be very strong and stiff whereas the transverse and shear properties are much lower. Bonded joints experience peel loading so the composite may fail in transverse tension before the adhesive fails. The composite adherend splits apart locally due to these peel stresses, thereby destroying the shear transfer capacity between the two adherends [3]. Some authors have studied the problem of peel stresses in adhesive joints with composites and found designs to reduce them. da Silva and Adams [4] propose an internal taper and adhesive fillet to reduce the peel stresses, however, these are not easy to manufacture. Other more sophisticated techniques have been proposed such as the use of z-pins to reinforce through the thickness strength of the composite $[5,6]$. However, the difficult and expensive manufacture process is a major drawback of this technique. It is therefore important to study adhesive joints with composites and find a reliable method to avoid the interlaminar failures that commonly occur for this material. These materials are used to manufacture a wide range of products. These composite materials are used for bathtubs, in sports gear, in the automotive industry, but 
mainly in the aerospace industry. The Boeing 787 airliner has a $50 \%$ use by weight of composite materials for its primary structure. This achievement was partly due to advances in adhesive bonding technology, which allows the efficient joining of such composite structures.

A type of composites used in the aeronautical industry is the fibre metal laminates (FML). Delft University of Technology first developed these materials. Their research found that the fatigue crack growth rates in adhesive bonded sheet materials can be reduced, if they are built up by laminating and adhesively bonding thin sheets of the material, instead of using on one thick monolithic sheet [7]. The FML concept could be extended to reinforce carbonfibre using metal, which is the research subject of this work. The concept has been usually applied to aluminium ( $\mathrm{Al}$ ) with aramid (ARALL) and glass fibres (GLARE), but it can also be applied to other constituents [8-12]. In particular, the GLARE material has been investigated intensively and has become one of the new materials used on the large Airbus A380 aircraft: two large sections of the fuselage and the leading edges of the horizontal tail planes are made of GLARE. Since metals and fibre-reinforced polymers have characteristic properties and features with respect to manufacturing, the manufacturing of hybrid materials has properties and features related to both material groups. This multilayer composition of the hybrid laminates also offers the opportunity to mix and combine constituent materials with the aim to optimize the component or substructure, creating a tailor-made material. Due to the potential in combining various metallic and composite materials, this technology still has a long way to go. This technology must be further explored in order to identify the optimum combinations of metallic and composite materials to be used in relation to potential applications or industry. The main challenge in the use of this technology is the recyclability. These materials need to be capable to have some mechanism of self-healing or dismantling in order to be possible to recycle separately each material (the metal and the composite).

Gomes et al. [13] used a concept similar to that used in FML's to increase the peel strength of traditional composite materials and hence increase the joint strength of hybrid laminates adhesive joints. The hybrid adherends of CFRP reinforced with Titanium sheets in the tops were used to manufacture the hybrid joints and compared with CFRP joints. They showed that these kinds of hybrid joints, compared with CFRP joints, prevent the delamination and increase the joint strength [13].

In the present study, the CFRP adherends were modified by including one and two aluminium sheets during the laminate manufacture to enhance the composite through the thickness properties. In order to evaluate the best method to improve adhesion between CFRP-Al, different surface treatment of aluminium was tested: untreated, sandblasted and anodised. The specimens with different surface treatments were tested under different loadings (tensile test in mode I, three point bending and peel test with a pre-crack). The objective was to identify the joint configuration that gives the best joint strength improvement in relation to the reference joint composed by CFRP adherends. A numerical study was carried out using
Table 1. Mechanical properties of AF 163-2K [13].

\begin{tabular}{ll} 
Tensile strength [MPa] & $46.93 \pm 0.63$ \\
Young's Modulus [GPa] & $1.52 \pm 0.12$ \\
Shear strength [MPa] & $46.86 \pm 2.57$ \\
$G_{I c}[\mathrm{~N} / \mathrm{mm}]$ & $4.05 \pm 0.07$ \\
$G_{I I c}[\mathrm{~N} / \mathrm{mm}]$ & $9.77 \pm 0.21$ \\
\hline
\end{tabular}

Table 2. Elastic properties of the CFRP [14].

\begin{tabular}{lll}
\hline$E_{x}=1.09 \mathrm{E} 5 \mathrm{MPa}$ & $v_{x y}=0.342$ & $G_{x y}=4315 \mathrm{MPa}$ \\
$E_{y}=8819 \mathrm{MPa}$ & $v_{x z}=0.342$ & $G_{x z}=4315 \mathrm{MPa}$ \\
$E_{z}=8819 \mathrm{MPa}$ & $v_{y z}=0.380$ & $G_{y z}=3200 \mathrm{MPa}$ \\
\hline
\end{tabular}

a finite element analysis with cohesive zone being employed to simulate the fracture behaviour of CFRP and hybrid laminates aluminium carbon-fibre joints.

\section{Experimental details}

\subsection{Adhesive}

The adhesive used was the AF 163-2K film adhesive, with $25.28 \mathrm{~kg} / \mathrm{m}^{2}$ of weight per area (nominal weight of $0.06 \mathrm{lb} /$ $\mathrm{ft}^{2}$ accordingly to the manufacturer), supplied by $3 \mathrm{M}$ Scotch-Weld. This is a modified epoxy structural adhesive with a knit supporting carrier, whose main function is to ensure the thickness of the adhesive layer. Table 1 shows the mechanical properties of the adhesive AF 163-2K [13].

\subsection{Adherends}

In the literature there are several studies that use the concept of FML's to improve the metal performance $[8,10$ 12]. However, the aim of this work was to improve the peel strength of CFRP using a similar concept of FML's. The lay-up was designed to maintain a ratio of 3:1 (by volume), $\mathrm{CFRP}$ and $\mathrm{Al}$ sheet, respectively. This ratio was chosen with the objective to reinforce the transverse properties of CFRP's. The adherends were fabricated with unidirectional carbon-epoxy pre-preg (SEAL ${ }^{\circledR}$ Texipreg HS 160 RM) with $0.15 \mathrm{~mm}$ thickness plies and $\left[0^{\circ}\right]_{16}$ lay-up (adherends with thickness of $3.2 \mathrm{~mm}$ ). CFRP is an orthotropic material, whose elastic mechanical properties can be seen in Table 2. The elastic mechanical properties of the CFRP correspond to the orientation of a $0^{\circ} \mathrm{CFRP}$ ply $(x-$ fibre, $y$ - transverse and $z$ - thickness directions). Table 2 shows the elastic properties of the CFRP [14].

The metal used as reinforcement was the 2024-T3 aluminium alloy. It is a high strength alloy and also has very good fatigue resistance. The 2024 alloy's main applications are aircraft structures and parts for the transportation industry. This aluminium alloy is used extensively to manufacture FMLs, as five out of six GLARE grades and two out of four ARALL laminates have 2024-T3 in their structure [15]. It is known that between 


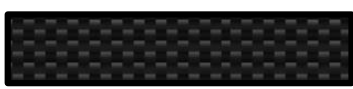

a) CFRP only

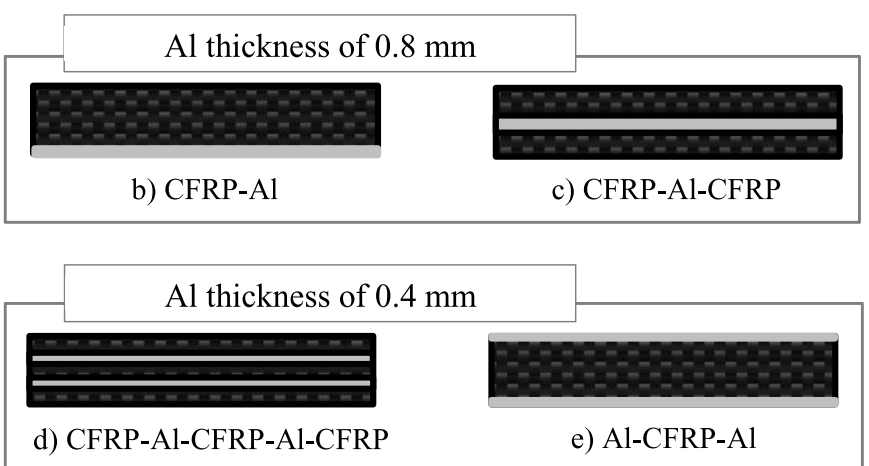

E- CFRP

2024-T3 Aluminium alloy

Fig. 1. Selected layups.

CFRP and aluminium, galvanic corrosion appears due to the difference of electrode potential, however, surface treatments have been developed (sulfuric acid anodization and hybrid sol-gel coating) which provide good protection against this phenomenon [16].

Sheets of aluminium with a thickness of 0.8 and $0.4 \mathrm{~mm}$ were used. Considering the ratio of $3: 1$ by volume, CFRP to $\mathrm{Al}$, and adherend thickness of $3.2 \mathrm{~mm}$, only one sheet of $\mathrm{Al}$ $(0.8 \mathrm{~mm})$ or two sheets of $\mathrm{Al}(0.4 \mathrm{~mm}$ each) were introduced in the laminates manufacturing. The adherends (CFRP and aluminium) were cured in a hot-press machine at $130{ }^{\circ} \mathrm{C}$ during $1 \mathrm{~h}$. Figure 1 shows the lay-up configurations used.

\subsection{Surface treatment influence}

The adhesion between CFRP and the $\mathrm{Al}$ alloy was studied in order to evaluate the bond quality. For that purpose, specimens with different surface treatments were manufactured. The mechanical behaviour of the specimen treated with each surface treatment was evaluated. Three surface treatment were performed

- As supplied - no surface treatment was applied to the aluminium sheet, only degreased with acetone.

- Sandblasted - a sandblasting machine was used to obtain a rougher surface and then the adherends were degreased with acetone.

- Phosphoric acid anodizing - the process of phosphoric acid anodizing (PAA) was used to anodise the aluminium sheets used. The treatment was performed according to ASTM D 3933-98 standard [17].

Square plates of $300 \mathrm{~mm}$, with different thicknesses and with different layups were manufactured. Hybrid laminates Al-CFRP plates with untreated aluminium (called as supplied) exhibited the worst adhesion. The CFRP debonded (Fig. 2a) on both sides of the aluminium, only due to the thermal stresses. Hybrid laminate plates with
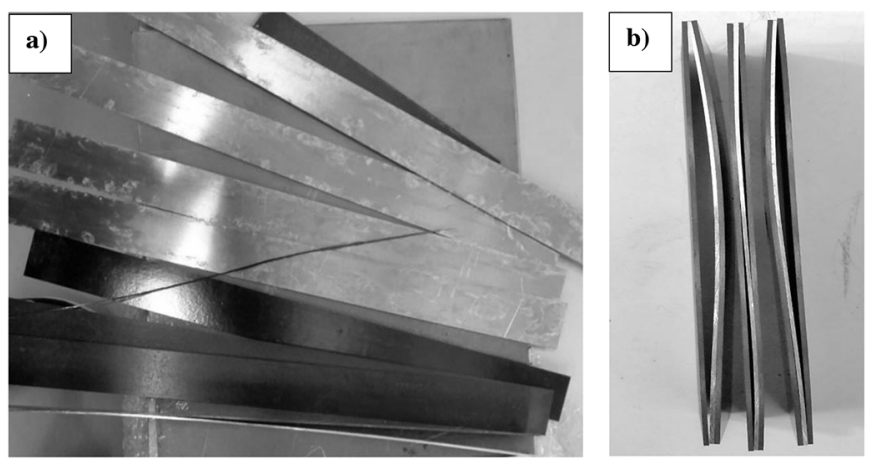

Fig. 2. Debonding of the Hybrid laminates Al carbon-fibre plates while cutting, (a) top view and (b) side view.

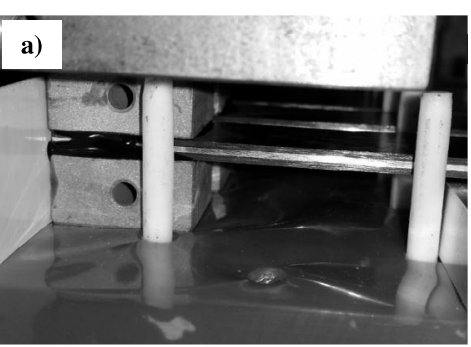

b)

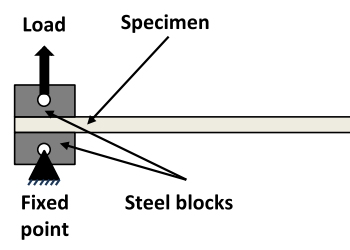

Fig. 3. Traction test in mode I; (a) specimen used in a mould, (b) loading scheme.

sandblasted aluminium exhibited better adhesion properties, but the debonding occurred while cutting (Fig. 2b) in around $75 \%$ of the cases while the rest debonded after a couple of days, due to residual thermal stresses. The thermal stress of hybrid adherends was numerically evaluated in Section 4.1.

The hybrid laminated plate where PAA surface treatment was applied on the aluminium exhibited a good adhesion compared to the other treatments. The adhesion was tested using three methods: tensile test in mode I, three point bending and a peel test with pre-crack. The tests (at least 3 specimens tested in each case) were performed in an INSTRON $^{\circledR}$ model 3367 universal test machine with a capacity of $30 \mathrm{kN}$ at room temperature and with a constant displacement rate of $1 \mathrm{~mm} / \mathrm{min}$.

\subsubsection{Tensile test in mode I}

To evaluate the adhesion properties between the anodised aluminium sheet and the CFRP, a tensile test in mode I was performed. The loading setup used is presented in Figure 3.

Figure 4 shows a representative load-displacement curve of the hybrid laminate adherend (CFRP-Al-CFRP) under mode I tensile test. The failure occurred in the CFRP layer and the average failure load was $14.52 \pm 1.37 \mathrm{kN}$.

\subsubsection{Three point bending}

Additional tests were conducted to evaluate the adhesion properties in mode II. In order to accomplish this, a 


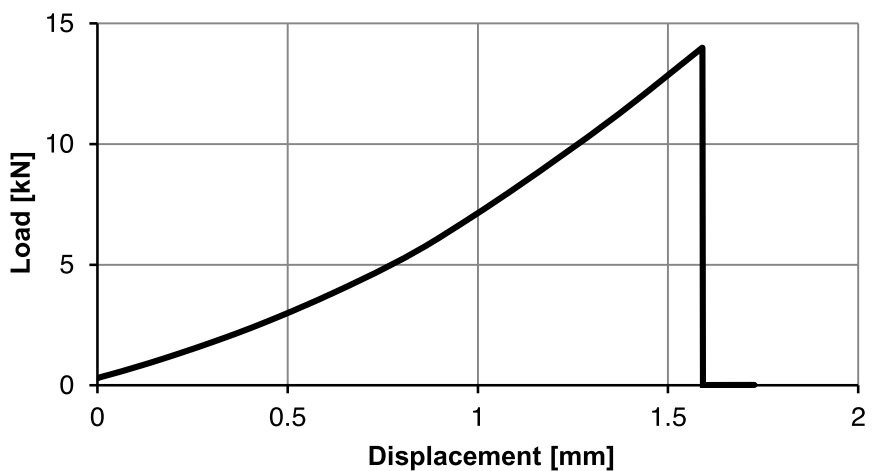

Fig. 4. Representative curve under mode I tensile test.

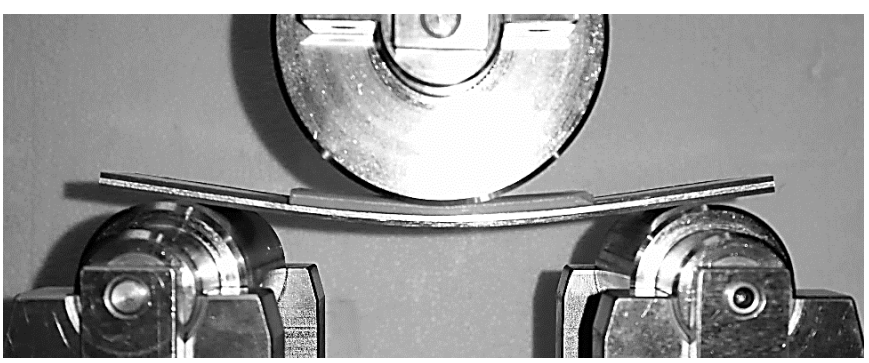

Fig. 5. Test setup used for the three point bending test.

three-point bending test was performed. The specimens were tested according to standard ASTM D 790-03 [18]. The setup configuration used in this test was a loading roller with a diameter of $60 \mathrm{~mm}$ and a piece of silicone rubber between the roller and the specimen, as shown in Figure 5. This setup was used to avoid the failure typical due to contact pressure.

Representative load-displacement curves are shown in Figure 6 , where a specimen made only of CFRP was tested for comparison purposes.

The failure of the hybrid laminate (CFRP-Al-CFRP configuration) adherend occurred in the upper CFRP region of the specimen due to compression stresses induced by the thermal contraction of the aluminium, while in the case of CFRP specimen the failure mode was a generalized fibre breakage through the thickness of the CFRP. The average results were $4.54 \pm 0.10 \mathrm{kN}$ for hybrid laminates specimens and $4.23 \pm 0.43 \mathrm{kN}$ for the CFRP specimens (by $7.3 \%$ ). The failure load of hybrid laminates specimens is slightly higher than CFRP specimens. Hybrid laminates specimens exhibited a good adhesion between CFRP and aluminium and no debonding occurred at the interface.

\subsubsection{Peel test with pre-crack}

In order to evaluate the cohesive properties of the interface $\mathrm{Al} / \mathrm{CFRP}$, specimens with a pre-crack were manufactured. The length of the pre-crack, between the load applied and the crack trip, was of $45 \mathrm{~mm}$. Figure 7 shows a representative load-displacement curve.

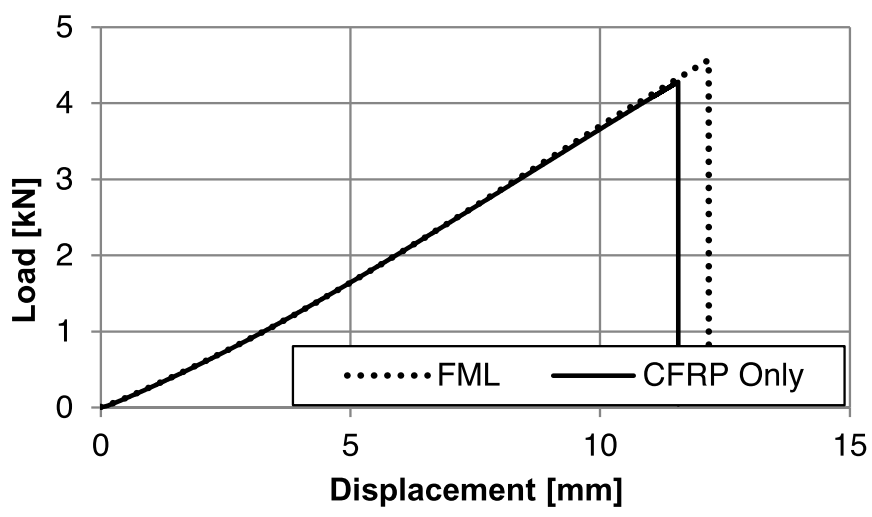

Fig. 6. Load-displacement curves under the three-point bending test.

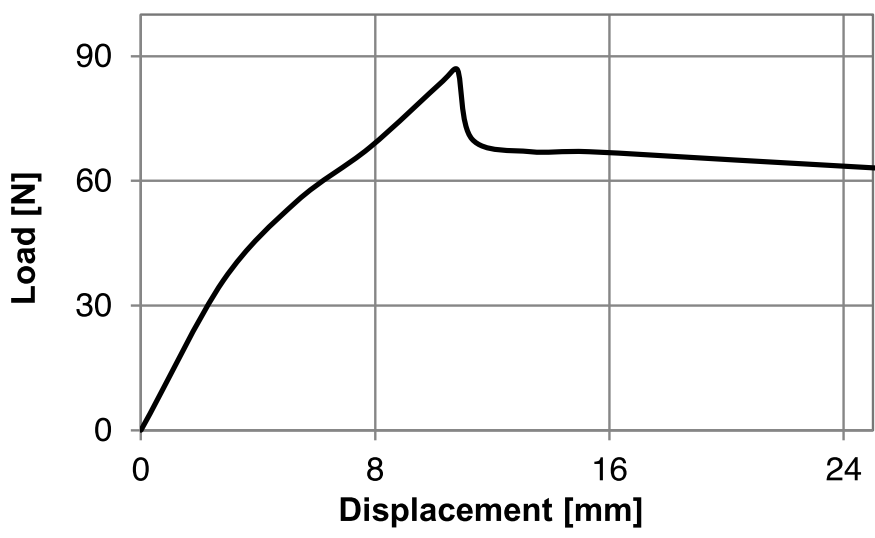

Fig. 7. Most representative curve for the peel test with a pre-crack.

Figure 8a shows the failure mode during the test and the failure surface (Fig. 8b) of the peel specimens with precrack. Figure 8 shows delamination of the CFRP during the peel tests. The adhesion between the CFRP and the aluminium surface which has been treated using PAA is stronger than the adhesion between the layers of carbon fibre. Due to these results (interlaminar failure of the CFRP), the results could not be used to determine the mode I fracture energy for the cohesive properties of the interface (the adhesion between Al-CFRP).

The bond between CFRP and anodised aluminium exhibited very good properties, stronger than the adhesion between the layers of CFRP. The three tests performed (tensile test in mode I, three point bending and peel test with pre-crack) indicate that the surface treatment of the aluminium with PAA is the best solution to obtain a good adhesion.

\subsection{Specimen geometry}

The main objective of this study was to increase the peel strength of composite materials and increase the joint strength of hybrid laminates aluminium carbon-fibre adhesive joints. To accomplish this objective, single lap joints (SLJs) with an overlap of $12.5 \mathrm{~mm}$ and $50 \mathrm{~mm}$ were 

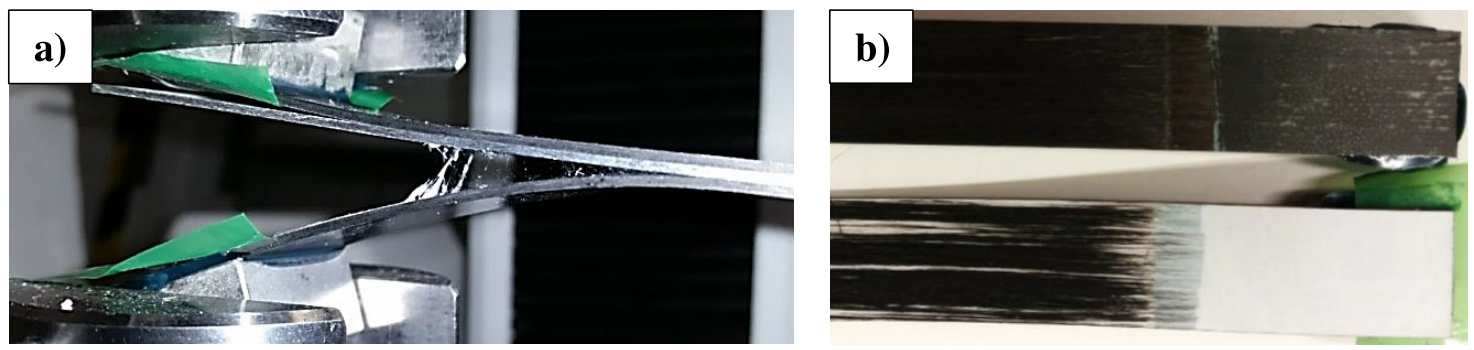

Fig. 8. Failure mode (a) and failure surface (b) of the peel specimen with pre-crack.
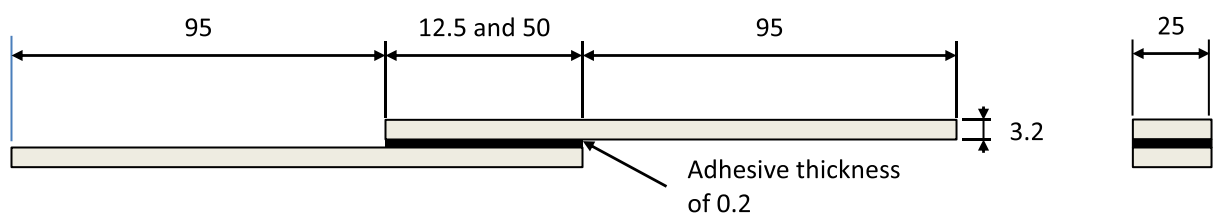

Fig. 9. Geometry of the single lap joints (all dimensions are in $\mathrm{mm}$ ).

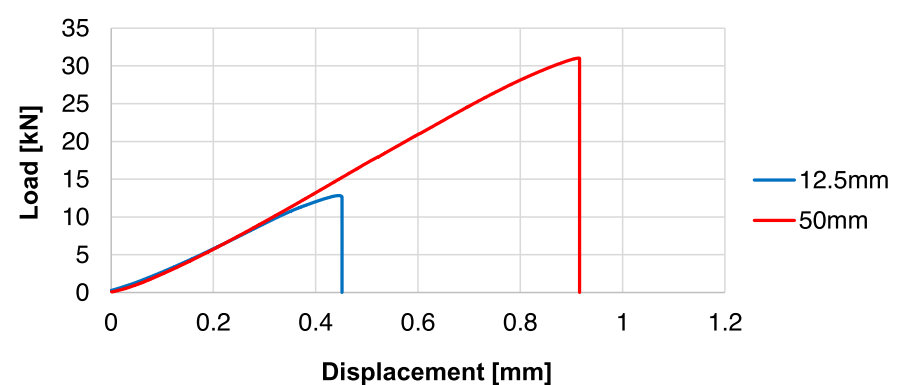

Fig. 10. Load-displacement curves obtained for CFRP joints.

manufactured. The width and adhesive thickness of the joints were the same for all hybrid laminates joints configuration $(25 \mathrm{~mm}$ and $0.2 \mathrm{~mm}$, respectively). The configurations of the joints are detailed in Figure 9.

\section{Experimental results of hybrid joints}

The tensile tests of the SLJ's were performed in a servohydraulic model, MTS ${ }^{\circledR}$ model 810 , with a load cell of $100 \mathrm{kN}$, with a displacement rate of $1 \mathrm{~mm} / \mathrm{min}$. Five specimens were tested to failure in laboratory ambient conditions (room temperature of $23{ }^{\circ} \mathrm{C}$, relative humidity of $55 \%)$.

\subsection{CFRP joint}

The purpose of this study was to assess the improvements of using different hybrid laminates aluminium carbon-fibre adhesive joints configurations. In order to have a benchmark to evaluate the differences between the different configurations, CFRP-only adherends were produced to serve as a reference for the other joints. Load-displacement curves for both $12.5 \mathrm{~mm}$ and $50 \mathrm{~mm}$ overlaps are presented in Figure 10.

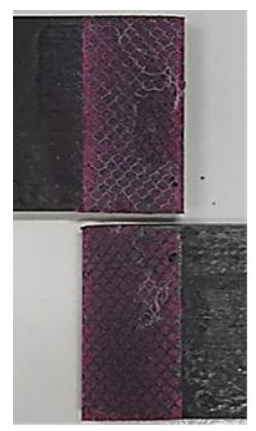

a

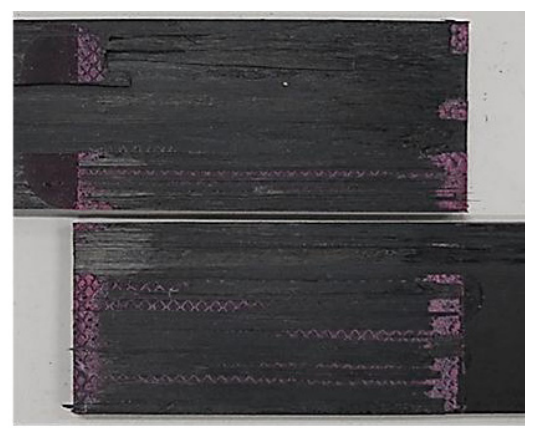

b
Fig. 11. Failure surface of the CFRP joints with an overlap of $12.5 \mathrm{~mm}$ (a) and overlap of $50 \mathrm{~mm}(\mathrm{~b})$.

Typical failure surface for both overlaps can be observed in Figure 11. The average failure load for CFRP-only joints was $12.5 \pm 0.4 \mathrm{kN}$ for the $12.5 \mathrm{~mm}$ overlap and $31.3 \pm 1.9 \mathrm{kN}$ for the $50 \mathrm{~mm}$ overlap. For the $12.5 \mathrm{~mm}$ overlap the failure was cohesive in the adhesive, whereas for the $50 \mathrm{~mm}$ overlap there was clear delamination of the adherends. The standard deviation for the experimental results with $50 \mathrm{~mm}$ overlap may be also affected by the unpredictability of the delamination failure.

\subsection{Hybrid laminated joint - CFRP-Al-CFRP}

The first configuration of aluminium-carbon fibre laminates consisted of CFRP reinforced with a $0.8 \mathrm{~mm}$ thick aluminium sheet in the middle of the adherend. The resultant load-displacement curves can be seen in Figure 12.

The failure mode of this type of joint with $12.5 \mathrm{~mm}$ of overlap length was cohesive (Fig. 13a) and with $50 \mathrm{~mm}$ of overlap length delamination occurred in the CFRP (Fig. 13b). 


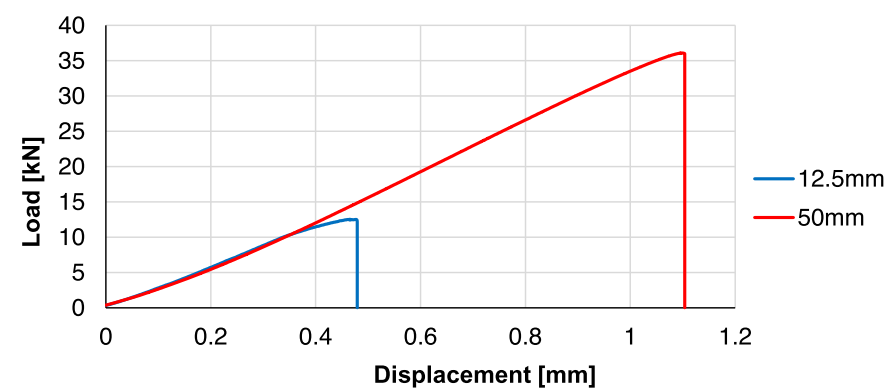

Fig. 12. Load-displacement curves obtained for hybrid joints with CFRP-AL-CFRP configuration.

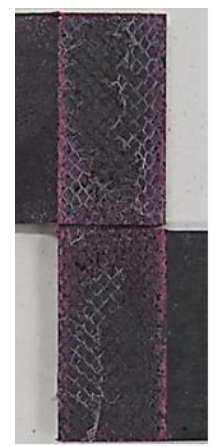

a

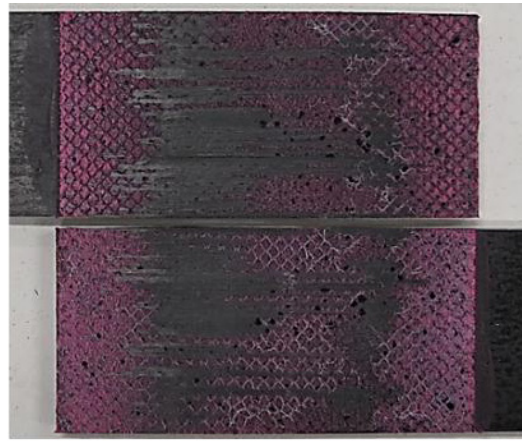

$\mathrm{b}$
Fig. 13. Failure surface of hybrid joint with CFRP-Al-CFRP configuration, overlaps of $12.5 \mathrm{~mm}$ (a) and $50 \mathrm{~mm}$ (b).

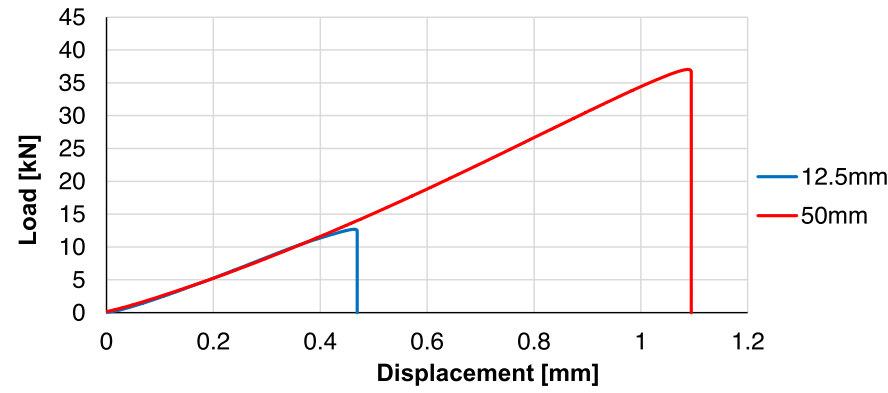

Fig. 14. Load-displacement curves obtained for hybrid joints with CFRP-AL-CFRP-AL-CFRP configuration.

For the hybrid joints with the adherend configuration CFRP-Al-CFRP, the joint strength was $13.0 \pm 0.5 \mathrm{kN}$ and $35.8 \pm 1.1 \mathrm{kN}$ for the $12.5 \mathrm{~mm}$ and $50 \mathrm{~mm}$ overlap, respectively. The failure load increases $3.5 \%$ for an overlap of $12.5 \mathrm{~mm}$ and $14.1 \%$ for an overlap of $50 \mathrm{~mm}$, when compared to the performance of CFRP-only joints.

\subsection{Hybrid laminated joint - CFRP-Al-CFRP-Al- CFRP}

The second configuration uses two sheets of aluminium with $0.4 \mathrm{~mm}$ of thickness to reinforce the composite.

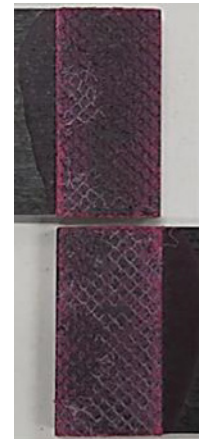

a

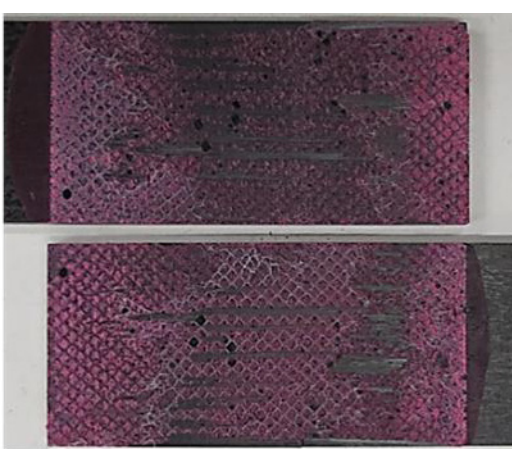

b
Fig. 15. Failure surface of hybrid joints with CFRP-AL-CFRPAL-CFRP configuration, overlaps of $12.5 \mathrm{~mm}$ (a) and $50 \mathrm{~mm}$ (b).

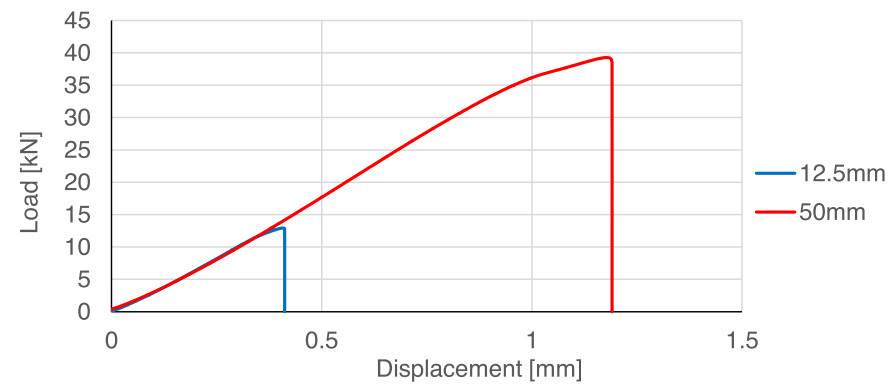

Fig. 16. Load-displacement curves obtained for hybrid joints with AL-CFRP-AL configuration.

Typical load-displacement curves for both overlap lengths are shown in Figure 14.

The failure surface of these joints with overlaps of 12.5 and $50 \mathrm{~mm}$ can be observed in Figure 15 .

The average failure load for this hybrid joint, with an overlap of $12.5 \mathrm{~mm}$, was $13.0 \pm 0.4 \mathrm{kN}$, which represents a slight increase of $3.8 \%$ in relation to the CFRP joint. For the hybrid laminated joint with an overlap of $50 \mathrm{~mm}$ $(36.6 \pm 0.8 \mathrm{kN})$ the failure load achieved was higher than the CFRP joint (16.8\%).

\subsection{Hybrid laminated joint - Al-CFRP-Al}

This configuration resembles the most classic concept of FML. In this case the core of the laminate is CFRP with an aluminium sheet of $0.4 \mathrm{~mm}$ on each top of the laminate. The load-displacement curves for $12.5 \mathrm{~mm}$ and $50 \mathrm{~mm}$ overlap are shown in Figure 16.

Figure 17 shows the failure surfaces of the hybrid joints with Al-CFRP-Al configuration, for both overlap lengths.

For the overlap of $12.5 \mathrm{~mm}$, the average failure load of this type of hybrid joints was $13.2 \pm 0.23 \mathrm{kN}$, which represents an improvement of $5.0 \%$ in relation to the CFRP joint. These hybrid joints with $12.5 \mathrm{~mm}$ exhibited the highest average failure load, but statistically not significantly. For an overlap of $50 \mathrm{~mm}$, the average failure load of this type of hybrid laminated joints was $39.48 \pm 0.51 \mathrm{kN}$, 
Table 3. Failure load and strength values for the CFRP and hybrid joints.

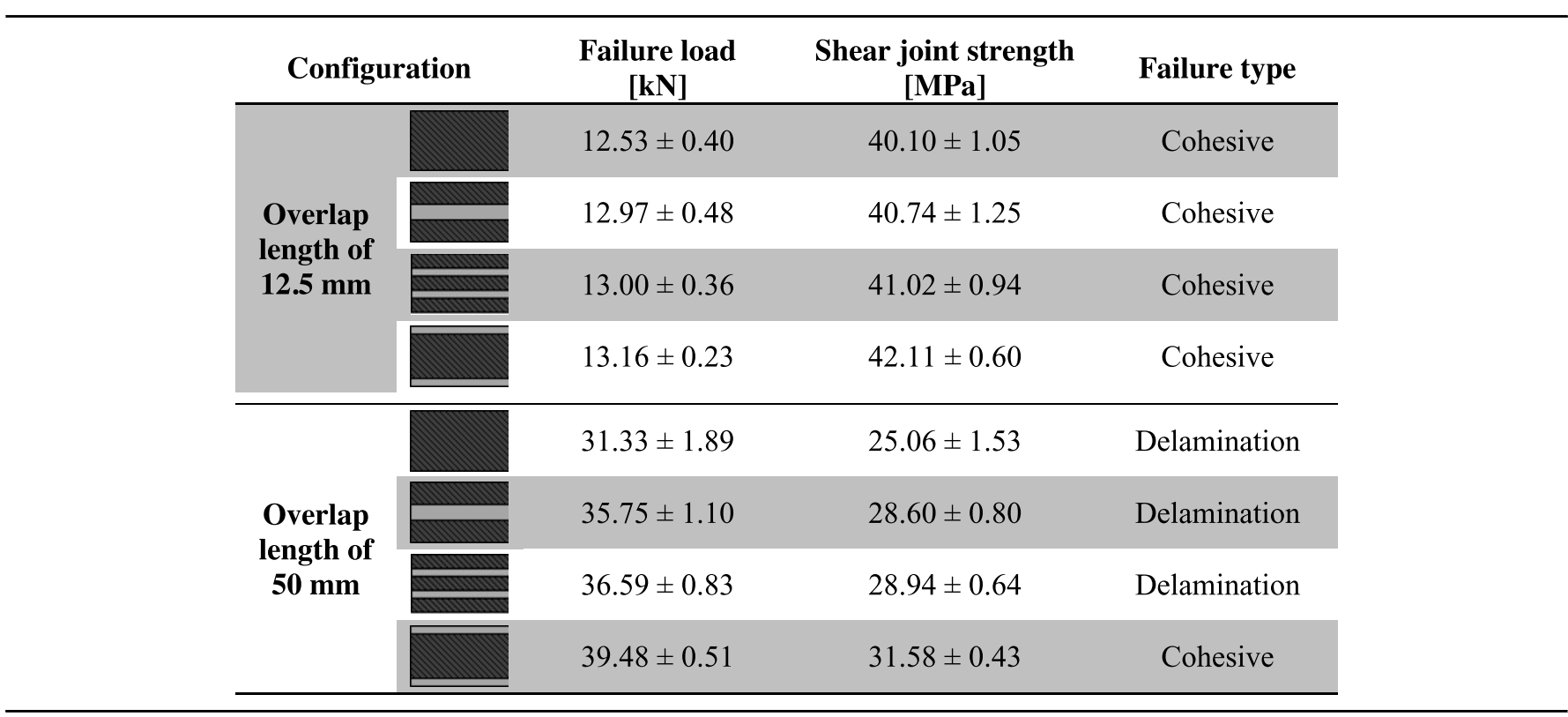

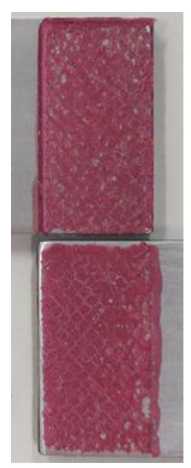

a

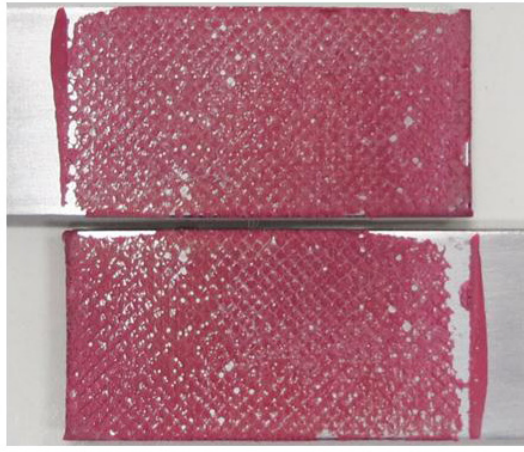

$\mathrm{b}$
Fig. 17. Failure surface of hybrid joint with AL-CFRP-AL configuration, overlaps of $12.5 \mathrm{~mm}$ (a) and $50 \mathrm{~mm}$ (b).

which represents an improvement of $26.0 \%$ in relation to the CFRP joint.

\subsection{Comparison of SLJ's results}

Table 3 summarizes the experimental results of the CFRP and hybrid joints for two overlap lengths (12.5 and $50 \mathrm{~mm}$ ).

A slight increase of the joint strength was observed in hybrid joints with an overlap of $12.5 \mathrm{~mm}$, but the load increase was smaller than the standard deviation obtained experimentally in the CFRP joints. The failure was cohesive in all specimens, and since the joint strength is more dependent on the adhesive rather than the adherends,

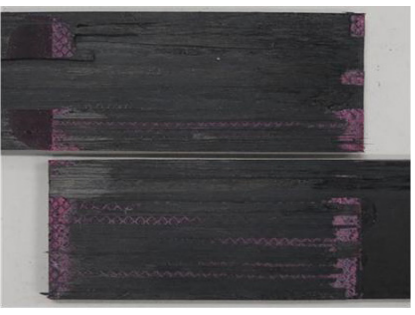

a

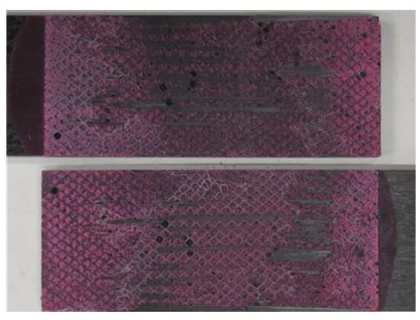

C

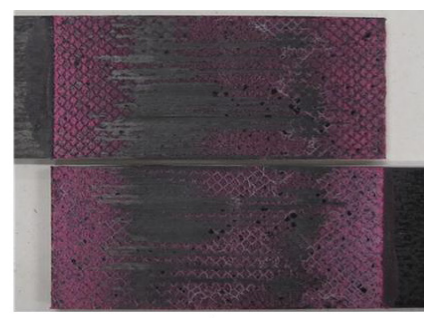

$\mathrm{b}$

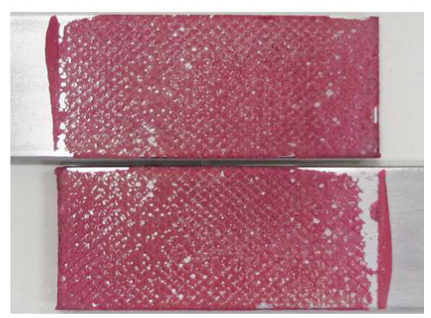

d
Fig. 18. Comparison of the failure surfaces of hybrid joints with an overlap of $50 \mathrm{~mm}$ : (a) CFRP-only; (b) CFRP-Al-CFRP; (c) CFRP-Al-CFRP-Al-CFRP; (d) Al-CFRP-Al.

this justifies the residual variation of joint strength as a function of hybrid joint configuration. For the $50 \mathrm{~mm}$ overlap, the CFRP joint suffered delamination. With the configurations CFRP-Al-CFRP and CFRP-Al-CFRP-AlCFRP, the failure mechanism was also delamination, but less severe when in comparison with the reference joint (see Fig. 18). This suggests an increase in the peel strength of the adherends, since the peel stresses are the major cause for the occurrence of delamination [19]. Regarding joint 


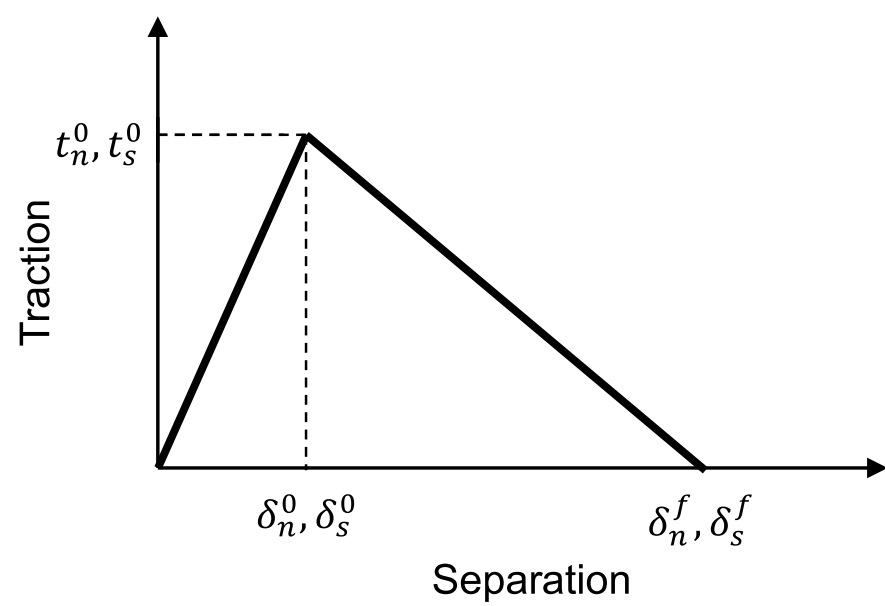

Fig. 19. Traction-separation law with linear softening law available in ABAQUS ${ }^{\circledR}$.

strength, an increase in the failure load was also verified, more significant than the increases for the $12.5 \mathrm{~mm}$ overlap. The failure mechanism was different for the Al-CFRP-Al configuration. It was cohesive in the adhesive, indicating a further improvement in the through-thickness properties relative to the other configurations. The fact that the CFRP layer is located further away than the adhesive layer reduces the effect of the peel stresses at the edges of the overlap in the CFRP. Since the failure was cohesive, and despite of the presence of an adhesive failure in some points, a more significant increase in the lap shear strength was expected, corresponding to the shear strength value for the adhesive.

\section{Numerical analysis of hybrid joints}

Cohesive zone model (CZM) can predict the formation and propagation of cracks [20,21]. The triangular CZM, due to its simplicity, is widely used and provides good results for most of the real situations [22]. This cohesive law is based on a relation between stresses and relative displacements (in tension or shear) connecting paired nodes of the cohesive elements (Fig. 19), to simulate an initial elastic behaviour up to $t_{n}^{0}$ (tension) or $t_{s}^{0}$ (shear). After the maximum stress is achieved, linear softening initiates. When the stress reaches the value of zero, no load can be transmitted, which is the same as saying that a crack has been created. $\delta_{n}$ and $\delta_{s}$ represent the normal and the shear maximum relative displacements, respectively.

FEA was performed using ABAQUS program (Dassault Systèmes Simulia Corp. Providence, RI, USA) using CZM by developing a $2 \mathrm{D}$ model to predict the failure loads and failure type for each hybrid metal laminates configuration. The adherends were modelled using a 4 node bilinear plane strain quadrilateral element (CPE4R), while the adhesive layer was modelled using a 4 node cohesive elements (COH2D4).

\subsection{Thermal stress evaluation}

CFRP have a very low coefficient of thermal expansion in the direction of the fibres, close to $0 \mu \mathrm{m} \mathrm{m}^{-1} \mathrm{~K}^{-1}$, while 2024-T3 aluminium alloy has a linear thermal coefficient of $22.8 \mu \mathrm{m} \mathrm{m}^{-1} \mathrm{~K}^{-1}$. To better understand the thermal stresses of hybrid laminates plates during the cure, an asymmetric lay-up (CFRP-Al) with a thickness of $3.2 \mathrm{~mm}$ and length of $300 \mathrm{~mm}$ (similar to the dimensions used experimentally) was numerically analysed. The CFRP used in this study cures at $130{ }^{\circ} \mathrm{C}$ for $1 \mathrm{~h}$ and then cools to room temperature. Therefore, in order to simulate the experimentally used cure process, in the numerical analysis a temperature gradient of $130{ }^{\circ} \mathrm{C}$ for the initial step and $20{ }^{\circ} \mathrm{C}$ (room temperature) for the final step was applied. The equivalent von Mises stress (Fig. 20) has a maximum value of $209 \mathrm{MPa}$ for the aluminium alloy and $163 \mathrm{MPa}$ for the CFRP in contact with the aluminium.

This analysis shows that the residual thermal stresses cannot be ignored when a material with different thermal expansion coefficients and asymmetric configurations (e.g. CFRP-Al) is used. The stress values due to thermal expansion are very high, considering the fact that the yield strength of this alloy is $289 \mathrm{MPa}$, and due to this fact this hybrid laminate configuration (CFRP-Al) was not used. This behaviour is in accordance with the study performed by $\mathrm{Fu}$ et al. [23], which showed that the thermal postbuckling deflection of hybrid laminates plates becomes significant with the increase of thermal loads. The other lay-up configurations are symmetric (e.g. CFRP-Al-CFRP or Al-CFRP-Al) and the thermal stresses present in the Al-CFRP interface are also symmetric and so the plate remains flat. After cooling, the residual thermal stresses of one Al-CFRP interface are alleviated by the symmetric configuration. The same behaviour is not observed for the plates that show asymmetric layup configurations, as in this case the residual thermal stresses can promote the buckling deflection of hybrid laminates plates after cooling.

\subsection{Hybrid joint model}

An FEM analysis was performed including geometrical non-linear effects and CZM was used to model the material behaviour. Triangular traction-separation laws were used to simulate the damage evolution. The composite adherends used are unidirectional, in order to properly simulate the experimental behaviour. The placement and orientation of the cohesive elements used in the models were selected in order to enable the reproduction of the experimentally identified failure. The mechanical properties of the material used are shown in Tables 1 and 2 . The models were locally refined in order to better simulate the experimental behaviour in locations where large stress concentration arise, such as at the ends of overlap length.

The boundary conditions were consistent in all the simulations and they are shown in Figure 21. The left end of the joint was fixed while in the right end a displacement was applied to replicate the loading. The joint was restrained transversely on the free ends of each adherends. 


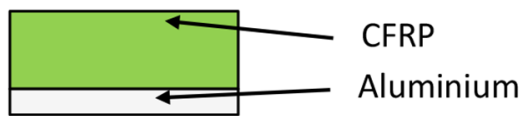

a)

b)

c)

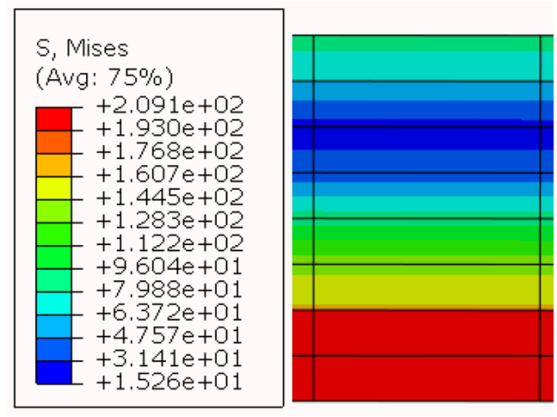

d)

Fig. 20. Thermal stress analysis of the CFRP-Al laminate: (a) lay-up of the model; (b) FEA mesh; (c) Equivalent von Mises stress plot (deformed view); (d) detail view of von Mises stress plot (units in MPa).

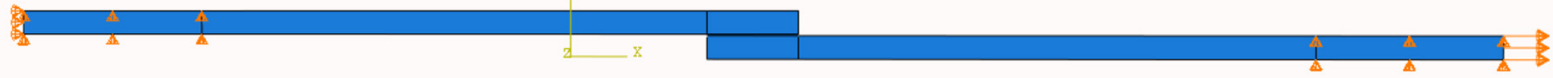

Fig. 21. Boundary conditions used.

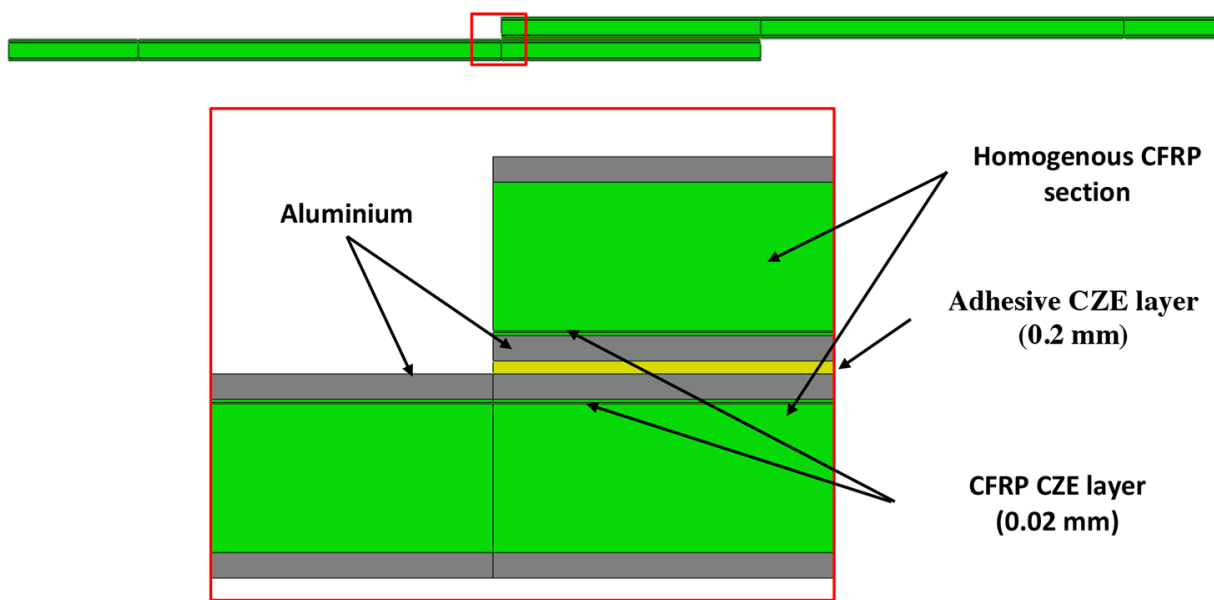

Fig. 22. (a) Hybrid laminates Al carbon-fibre joint with Al-CFRP-Al configuration with 50 mm of overlap; (b) enlarged detail view in which the CZE layers can be observed.

In order to properly simulate the delamination process, a cohesive element layer $(0.02 \mathrm{~mm}$ thick $)$ was introduced in the adherend, at a distance of $0.05 \mathrm{~mm}$ from the adhesive layer (for configurations CFRP-Al-CFRP and CFRP-Al-
CFRP-Al-CFRP) or at a distance of $0.05 \mathrm{~mm}$ from the $\mathrm{Al}$ layer (for configuration Al-CFRP-Al). Figure 22 shows a detailed view of Al-CFRP-Al joint with an overlap of $50 \mathrm{~mm}$. 
Table 4. Comparison between the damage obtained by FEA (damage variable SDEG) and experimentally for the CFRP joint.

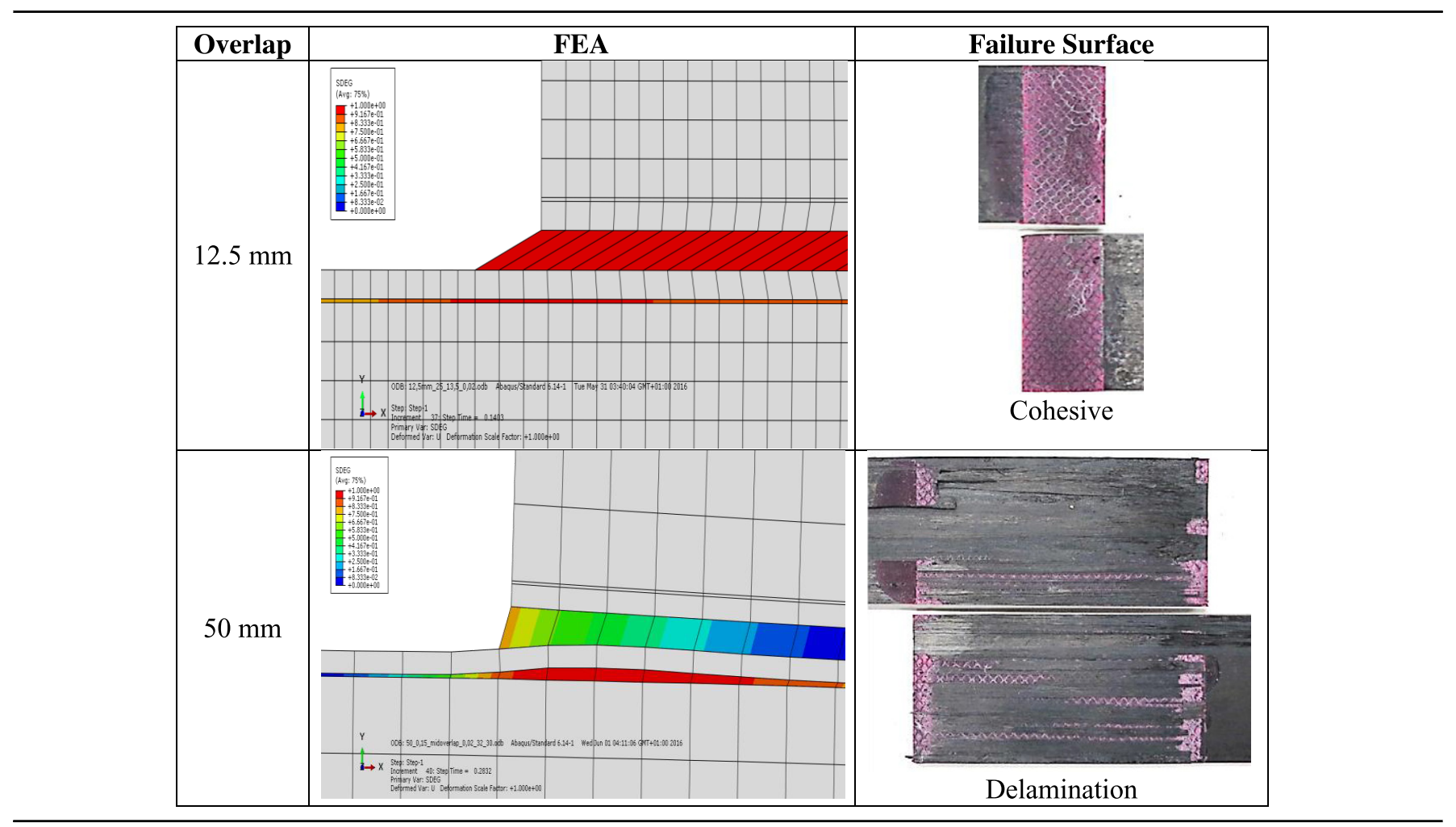

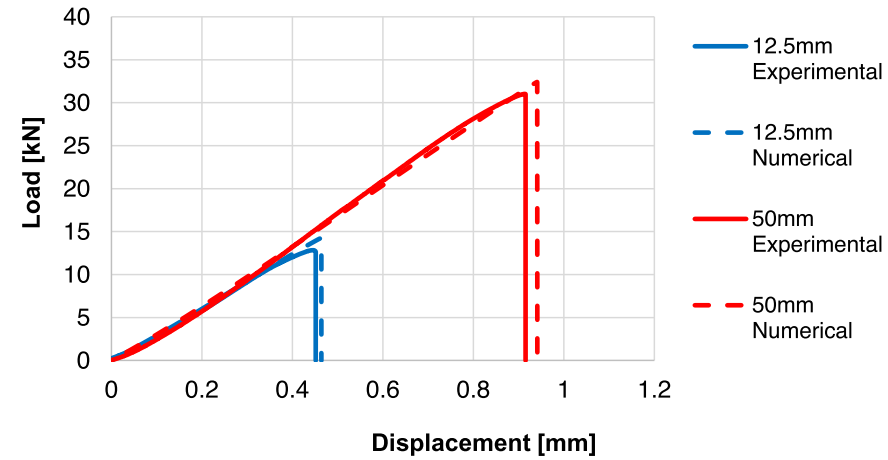

Fig. 23. Comparison between the experimental and the FEA load vs displacement curves for CFRP joints.

The thermal residual stresses due to the difference in the thermal expansion coefficient between CFRP and aluminium are a major concern for this type of material. In order to take into account the physical behaviour that occur during the cure process of the joints, an intermediate step before applying the displacement is created, with the cure temperature of the adhesive. In the following step, room temperature was imposed. This difference in temperature will simulate the effect of the cure of the adhesive in the hybrid adherends, and consider the thermal residual stresses existent in the adherends. The CTE for CFRP was considered $0 \mu \mathrm{m} / \mathrm{m} \mathrm{K}^{-1}$.

\subsection{Strength prediction}

The load displacement curves obtained from the FEA for both 12.5 and $50 \mathrm{~mm}$ are compared with experimental curves in Figure 23.

Despite the fact that the predictions are slightly higher, the model can be considered accurate and is able to give a good prediction for the failure load. The damage obtained by FEA occurs when the scalar stiffness degradation variable (SDEG) reaches 1. For values of SDEG higher than zero signifies that the damage starts. In Table 4 it is possible to compare the type of failure predicted by the FEA analysis and the failure surfaces for both overlaps.

In the numerical models, for an overlap of $12.5 \mathrm{~mm}$, the damage occurs first in the adhesive, with the CZE in the carbon fibre already damaged. For the $50 \mathrm{~mm}$ overlap, it is clear that the damage in the CZE of the carbon fibre reaches its peak first, while there is already some damage in the adhesive at the edges of the overlap. These results are coherent with the experimental data, where the delamination of the adherends was evident, with the adhesive at this edges showing a slightly different colour than the rest of the bonded length, indicating some plastic deformation. This is explained by the stress concentration on the edges of the bonded area, where the peel stresses are maximum.

Regarding the numerical results for the hybrid joints, both CFRP-Al-CFRP and CFRP-Al-CFRP-Al-CFRP configurations showed the same behaviour as the CFRP 
Table 5. Comparison between the damage obtained by FEA (damage variable SDEG) and experimentally for the hybrid joints with Al-CFRP-Al configuration.

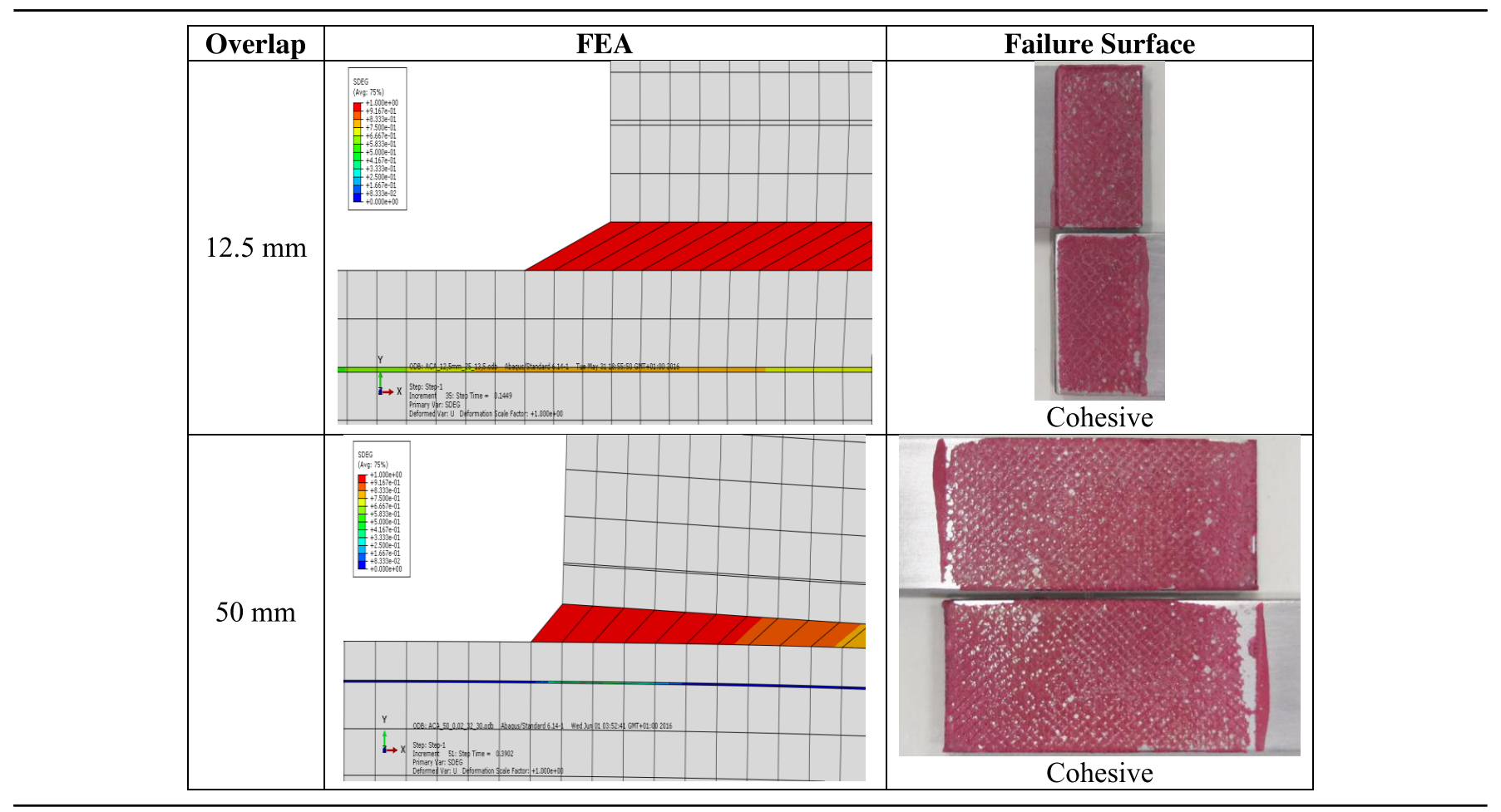

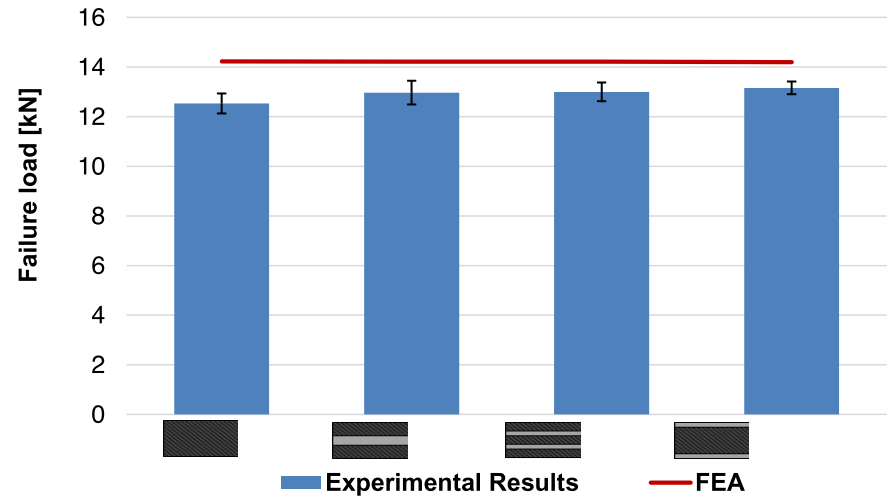

Fig. 24. Comparison between FEA predictions and experimental results for the failure load of specimens with a $12.5 \mathrm{~mm}$ overlap.

joints. The failure was cohesive in the adhesive for the $12.5 \mathrm{~mm}$ overlap and delamination in the hybrid adherends occurred for the $50 \mathrm{~mm}$ overlap. For the hybrid joints with Al-CFRP-Al configuration, the damage predicted by the FEA and the fracture surface obtained experimentally for this lay-up are shown in Table 5 .

As obtained experimentally, the FEA analysis for the Al-CFRP-Al configuration resulted in a cohesive failure for both overlaps. In both cases there is some damage in the

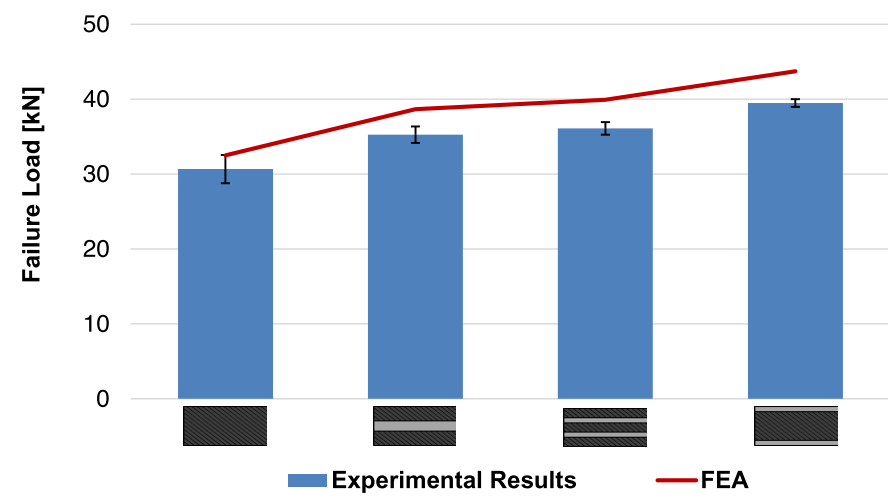

Fig. 25. Comparison between FEA predictions and experimental results for the failure load of specimens with a $50 \mathrm{~mm}$ overlap.

CFRP cohesive layer, but it is clear that the failure occurs in the adhesive. It is possible to conclude that all the models predicted correctly the failure mode for all the lay-up configurations and overlaps.

\section{Discussion of hybrid joints performance}

Figures 24 and 25 compare the experimental and prediction results of the joints. 

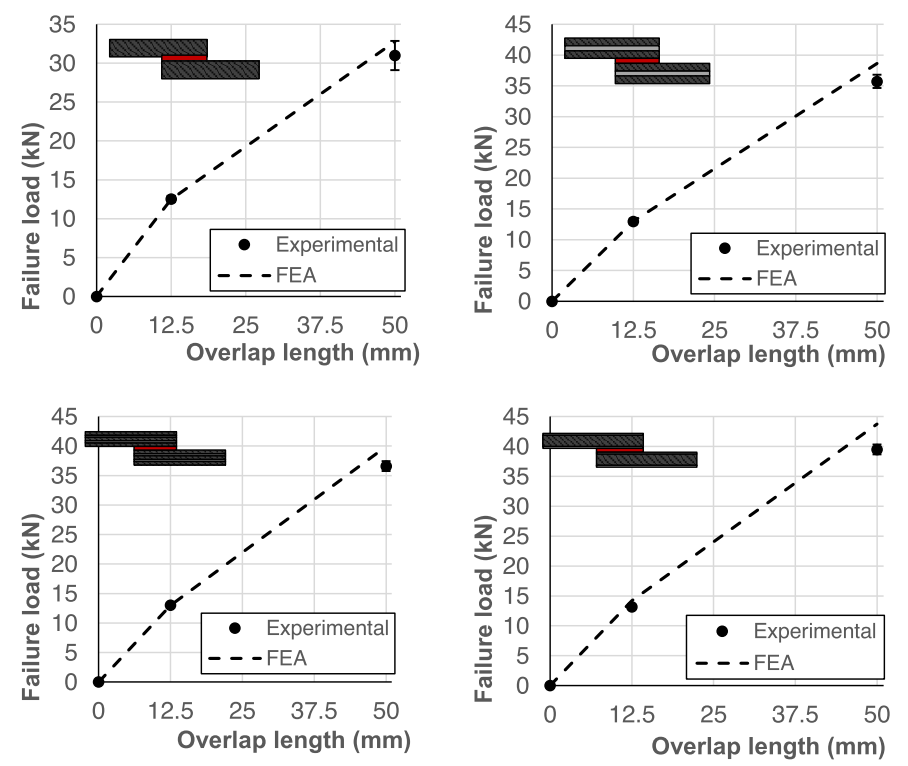

Fig. 26. Influence of the overlap length on the joint strength.

For the joints with overlap of $12.5 \mathrm{~mm}$, all the predictions were coherent with the experimental results, although with a higher failure load (Fig. 24). Regarding the failure surfaces for all joints the failure was cohesive in adhesive. The failure load for all joints were similar, this fact indicates that the adhesive reached the maximum strength performance.

For the $50 \mathrm{~mm}$ overlap, the trend of the predictions matches accurately the experimental results (Fig. 25). The highest joint strength was achieved for hybrid joints with Al-CFRP-Al configuration. This indicates that for these configurations the aluminium surface prevents the delamination of the adherends and provides the adhesive to work to its full potential.

Figure 26 shows the joint strength increases as a function of overlap length. The joints with adhesive bonded with the CFRP were observed that an increase in bonded area does not translate into linear increase of the joint strength. This behaviour was due to delamination of joints with an overlap of $50 \mathrm{~mm}$, and independently of the adherend configuration the joint strength was similar. Before reaching the delamination of adherend the adhesive deformed plastically, permitting a slight increase as a function of overlap length. For the hybrid joints with configuration Al-CFRP-Al, an almost linear increase of joint strength as a function of overlap length was observed. This linear increase is due to ductile adhesive performance that allows a uniform load transfer over the joint length [24] and this leads to a joint strength increase [25]. Overall, the numerical model replicates the results obtained experimentally with a good accuracy.

Overall, the finite element model replicates the results obtained experimentally with reasonable accuracy. The model used to simulate the CFRP and hybrid joints was found to be accurate enough and as a consequence, numerical simulations can be used to design this type of joints.

\section{Conclusion}

The main objective of this work was the study of CFRP joints strength using hybrid joints. In order to accomplish this goal, the influence of surface treatment on the bond properties between the aluminium sheet and the CFRP was experimentally studied. Experimental tests and numerical simulations were conducted to evaluate the strength of the joints designed.

This study showed that PAA was the best surface treatment to use in order to ensure a good adhesion between the aluminium and CFRP. The adhesion properties obtained with this surface treatment applied to aluminium were better than the adhesive properties between the laminas of CFRP.

The thermal stresses analysis showed that high residual thermal stresses are present in the hybrid joints, due to the very low thermal expansion coefficient of CFRP and the high expansion of aluminium. The average equivalent von Mises stress is higher than half of the yield strength of the aluminium alloy.

This study showed that the strength of hybrid joints is highest when the aluminium (Al-CFRP-Al) is used in the external layers of the lay-up and prevents delamination.

For overlap lengths of $50 \mathrm{~mm}$ the hybrid joints that have aluminium in the middle (e.g. CFRP-Al-CFRP and CFRP-Al-CFRP-Al-CFRP configurations), exhibit slightly higher strength values than the CFRP joints, but this increase is not statistically significant and the failure surfaces obtained were by delamination.

The numerical models developed in ABAQUS ${ }^{\circledR}$ showed a good agreement with the joint strength obtained experimentally.

R.J.C. Carbas would like to thank the Portuguese Foundation for Science and Technology (FCT) for supporting the work presented here through the individual grant $\mathrm{SFRH} / \mathrm{BPD} /$ $96992 / 2013$.

\section{References}

1. M.D. Banea, L.F.M. Silva, Adhesively bonded joints in composite materials: an overview, Proc. Inst. Mech. Eng. P. L J. Mater. Des. Appl. 223 (2009) 1-18

2. R.A. Pethrick, Design and ageing of adhesives for structural adhesive bonding - a review, Proc. Inst. Mech. Eng. P. L J. Mater. Des. Appl. 229 (2015) 349-379

3. L.F.M. da Silva, A. Öchsner, R.D. Adams, Handbook of Adhesion Technology, Springer, Berlin, 2011

4. L.F.M. da Silva, R.D. Adams, Techniques to reduce peel stresses in adhesive joints with composites, Int. J. Adhes. Adhes. 27 (2007) 227-235 
5. T.M. Koh, S. Feih, A.P. Mouritz, Strengthening mechanics of thin and thick composite T-joints reinforced with z-pins, Compos. P. A Appl. Sci. Manuf. 43 (2012) 1308-1317

6. S. Ucsnik, M. Scheerer, S. Zaremba, D.H. Pahr, Experimental investigation of a novel hybrid metal-composite joining technology, Compos. P. A Appl. Sci. Manuf. 41 (2010) 369-374

7. A. Asundi, A.Y.N. Choi, Fiber metal laminates: an advanced material for future aircraft, J. Mater. Process. Technol. 63 (1997) 384-394

8. R. Alderliesten, On the development of hybrid material concepts for aircraft structures. Recent Pat. Eng. 3 (2009) $25-38$

9. C.A.J.R. Vermeeren, An historic overview of the development of fibre metal laminates, Appl. Compos. Mater. 10 (2003) 189-205

10. S. Hinz, T. Omoori, M. Hojo, K. Schulte, Damage characterisation of fibre metal laminates under interlaminar shear load, Compos. Part A 40 (2009) 925-931

11. H. Nakatani, T. Kosaka, K. Osaka, Y. Sawada, Damage characterization of titanium/GFRP hybrid laminates subjected to low-velocity impact, Compos. Part A 42 (2011) 772-781

12. P. Cortés, W.J. Cantwell, The fracture properties of a fibremetal laminate based on magnesium alloy, Compos. Part B 37 (2006) 163-170

13. D.G.D. Santos, R.J.C. Carbas, E.A.S. Marques, L.F.M. da Silva, Reinforcement of CFRP joints with fibre metal laminates and additional adhesive layers, Compos. Part B Eng 165 (2019) 386-396

14. X. Shang, E.A.S. Marques, J.J.M. Machado, R.J.C. Carbas, D. Jiang, L.F.M. da Silva, A strategy to reduce delamination of adhesive joints with composite substrates, Proc. Inst.
Mech. Eng. P. L J. Mater. Des. Appl. 233 (2019), $521-530$

15. T. Sinmazçelik, E. Avcu, M.Ö. Bora, O. Çoban, A review: fibre metal laminates, background, bonding types and applied test methods, Mater. Des. 32 (2011) 3671-3685

16. W.X. Wang, Y. Takao, T. Matsubara, Galvanic corrosionresistant carbon fiber metal laminates, in Procedings of ICCM-16 Conference, Kyoto, July, 2007

17. ASTM D 3933-98. Standard Guide for Preparation of Aluminium Surfaces for Structural Adhesives Bonding (Phosphoric Acid Anodizing), 1998

18. ASTM D 790-03. Standard test methods for flexural properties of unreinforced and reinforced plastics and electrical insulating materials, 2003

19. L.J. Hart-Smith, Adhesive-bonded single-lap joints, NASA Langley contract report NASA CR-112236, 1973

20. L.F.M. da Silva, R.D.S.G. Campilho, Advances in numerical modelling of adhesive joints, Springer Briefs in Computational Mechanics, 2012

21. R.A. Sauer, A survey of computational models for adhesion, J. Adh. 92 (2016) 81-120

22. C.D.M. Liljedahl, A.D. Crocombe, M.A. Wahab, I.A. Ashcroft, Damage modelling of adhesively bonded joints, Int. J. Fract. 141 (2006) 147-161

23. Y. Fu, J. Zhong, Y. Chen, Thermal postbuckling analysis of fiber-metal laminated plates including interfacial damage, Compos. Par B 56 (2014) 358-364

24. D.F.S. Saldanha, C. Canto, L.F.M. da Silva, R.J.C. Carbas, F.J.P. Chaves, K. Nomura, T. Ueda, Mechanical characterization of a high elongation and high toughness epoxy adhesive, Int. J. Adhes. Adhes. 47 (2013) 91-98

25. M. Goland, E. Reissner, The stresses in cemented joints, J. Appl. Mech. 11 (1944) A17-A27

Cite this article as: Ricardo J.C. Carbas, Miguel P. Palmares, Lucas F.M. da Silva, Experimental and FE study of hybrid laminates aluminium carbon-fibre joints with different lay-up configurations, Manufacturing Rev. 7, 2 (2020) 